\title{
Components Topology of Oracle Bones Characters
}

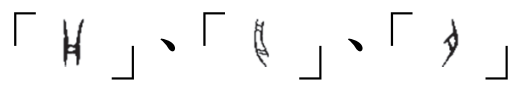 \\ Julian Juhi-Lian Ting \\ tingjulian@gmail.com \\ http://amazon.com/author/julianting
}

\begin{abstract}
Oracle bones characters have many variations. As they are still conceivable, there must have some intrinsic essence inside. Disputes of previous studied components $\ulcorner H\lrcorner\ulcorner\lrcorner\ulcorner\downarrow\lrcorner$ exist, while some interpretation are too far -fetched. We introduce some concepts from fluid dynamics and graph theories to interpret the meaning of these components in $\ulcorner$ 舟」、「般」、「盤」、 $\ulcorner$ 凡、「風」、「鳳」、「服」、「受」、「前」、「朕」.
\end{abstract}




\title{
初探甲骨文中「月」「护的拓樸學
}

丁致良

德曹研究院漢學研究所

tingjulian@gmail.com

http://amazon.com/author/julianting

\begin{abstract}
摘要:
甲骨文字變形極多, 卻仍能為人所辨識, 顯示其中必有不變的特徵。前人研究甲骨文中 部件 $\ulcorner H\lrcorner\ulcorner 」\ulcorner\oint 」$ 的意義有認為相同, 也有認為不同; 但是有些解釋太過率強。 本文引入流體力學及拓樸學的觀念，針對前人討論過的 $「$ 舟」「般」「盤」「凡」「風」、 $\ulcorner$ 鳳」「服」「受」「前」「朕」等字中該部件之意義加以闡明。至於同與不同端視觀 察者所使用的工具、語言及抽象化的程度而定 ; 難以一言蔽之。
\end{abstract}

關鍵字：甲骨文、離散數學、拓樸學、流體力學

\section{一、前言}

甲骨文字從 1899 年發現以來解釋的人很多, 有些令人信服, 有些卻有爭議; 有些人 引經據典，展現他的國學素養，但是所提出的看法卻難令人苟同。這些論點大都是從國 學的觀點出發。前人對前前人於甲骨文的詮釋提出批評的也大有人在。例如, 關於天干、 地支的解釋《說文解字》引用《太經》及郭沫若的〈釋支干〉的解釋都被批評為「不 可靠」, 甚至「荒誕」 1 。原因之一是提出各種說法的人沒有一個是商朝人物, 因此不具 權威性, 只能說某些人的看法可能比較好而已。也就是說甲骨文的意義是需要詮釋的。

甲骨文字變形極多, 但是卻仍能為人所辨識, 顯示這些變形中應該具備某些特徵仍 然不變。數學上探討這種在變形後能維持不變的特徵的學問稱為拓樸學 (topology)。幾何 圖形在變形後仍然維持相同特徵的稱為同構 (isomorphic) 或同胚 (homeomorphic) ${ }^{2}$ 。通 常這些特徵包含節點數、線段數及切割平面數。

安也致及徐海寧 ${ }^{3}$ 、出野文莉 $(\text { 張莉 })^{4}$ 分別討論過甲骨文中「月」與「」這個部

1 朱岐祥, 《甲骨文讀本》, (台北市, 里仁書局, 1999 年), 頁 2 。

2 Ting Julian : 《Discrete Mathematics》, (AMAZON : creativespace, 2013)。

3 安也致、徐海寧 :〈古代亀卜文化の字 における表現ついて 一一胃「船」形偏旁の意味の検討 〉 《駒沢史学 駒沢史学》52 号, 1999 年, 頁 87-97。 
件出現在 $「$ 舟」「般」「盤」「凡」「風」「鳳」「服」「受」「前」「朕」等字中的 意義。下面我們運用一些近代自然科學的觀念來探討這幾個字。希望能在其中尋找一些 不變的特徵。

$$
\text { 二、「舟」「「般」及「盤」 }
$$

這幾個字由簡到繁別具意義。

$\ulcorner$ 舟」寫成 的確是象形, 並非如前人所言為假藉。那是一葉扁舟或者說就是個舢 舨、竹筏。在國畫中的確是這樣畫的。在我們查得到的 17 個例子中沒有一個例外。而 且都是畫得稍微有一點傾斜。因此我們要問：傾斜在「舟」的甲骨文中是不是一個重要 特徵? 中間連結的數目及兩條槓彎曲與否似乎並非重點。從這 17 例中也許我們可以歸納 $\ulcorner$ 舟」的特徵為：有一點傾斜的兩條槓中間加上幾條短槓連結；雖然傾斜這件事並不算 是拓樸特性。但是無論如何，要把這個字解釋成與神靈交流就太過牽強了。

\begin{tabular}{|c|c|c|c|c|}
\hline $\begin{array}{l}\text { Dy } \\
\text { 甲 } 637 \text { 合 } \\
34483 \\
\text { 歷組 }\end{array}$ & $\begin{array}{l}\text { 甲 } 1032 \\
\text { 合 } 27816 \\
\text { 何組 }\end{array}$ & $\begin{array}{c}\text { A } \\
\text { 乙 } 930 \\
\text { 合 } 11460 \\
\text { 賓組 }\end{array}$ & $\begin{array}{c}X \\
\text { 前 } 7.21 .3 \\
\text { 合 } 16940\end{array}$ & $\begin{array}{c}\text { A } \\
\text { 前 } 7.24 .2 \\
\text { 合 } 7329 \\
\text { 賓組 }\end{array}$ \\
\hline $\begin{array}{l}\text { Din } \\
\text { 林 } 2.11 .8 \\
\text { 合 } 11615\end{array}$ & $\begin{array}{l}\text { D. } \\
\text { 暗 } 4.7 \\
\text { 合 } 32555 \\
\text { 歷組 }\end{array}$ & $\begin{array}{c}\text { A } \\
\text { 粹 } 901 \\
\text { 合 } 33263 \\
\text { 歷組 } \\
\end{array}$ & $\begin{array}{c}\text { A } \\
\text { 粹 } 1059 \\
\text { 合 } 32850 \\
\text { 歷組 }\end{array}$ & $\begin{array}{c}\text { H } \\
\text { 鄴 } 3 \text { 下.39.3 } \\
\text { 合 } 32834 \\
\text { 歷組 } \\
\end{array}$ \\
\hline $\begin{array}{c}H \\
\text { 摄 } 1.453 \\
\text { 合 } 8032 \\
\text { 賓組 } \\
\end{array}$ & $\begin{array}{c}\text { H } \\
\text { 佚 } 968 \\
\text { 合 } 4930 \\
\text { 賓組 }\end{array}$ & 燕 159 & $\begin{array}{l}\text { } \\
\text { 珠 } 1382 \\
\text { 合 } 4926\end{array}$ & $\begin{array}{c}\text { 京津 } 2439 \\
\text { 合 } 11463\end{array}$ \\
\hline $\begin{array}{c}\text { U } \\
\text { 寧渥 } 1.183 \\
\text { 合 } 32522 \\
\text { 歷組 } \\
\end{array}$ & $\begin{array}{c}\text { A } \\
\text { 京都 } 2522 \\
\text { 合 } 32851\end{array}$ & & & \\
\hline
\end{tabular}

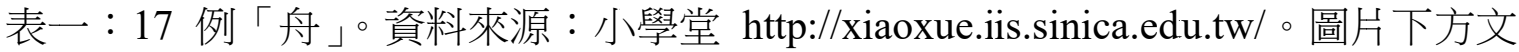
字為字型出處, 依照小學堂慣例。

4 出野文莉 : 〈甲骨文「月」符號之原義〉《第 27 屆中國文字學國際學術研討會論文集》, 2016 年, 頁 $251-262$ 。 
類似字如 $「$ 般」肷, 一般解釋為河川上搬運。以手執長棍, 擺渡船隻。左邊是船隻, 右手邊師是手, 中間 $\mathrm{T}$ 形為長棍。在我看來陸上用板車搬運也可以吧！? 至於舟與板子 到底差多少? 我看來是一樣的。一塊板子的確可以當船, 當然要大塊一點, 四周再加上 竹筒更好。這是流體力學 ${ }^{5}$ 。

比「般」再複雜一點的「盤」並沒有甲骨文，但有金文 $「$ 䇥」。「皿」上面放的是甚 麼東西? 在我看來 $\mid h$ 是放在上面的一個東西; 有人說是一片肉; 在甲骨文中 $\ulcorner$ 肉, $\ulcorner\oint 」$, 並不是這麼寫得。學數學的人談論拓樸學 : $\ulcorner$ h」與 $\ulcorner y 」$ 的拓樸並不一樣吧！? 前者 有四個節點, 後者只有三個 ${ }^{6}$ 。而且並非兩條槓。在我查得到的五個肉字, 都沒有像 $\ulcorner$ H」 具有四個節點而且出頭的。解釋成「盤」有盤旋之意等等都太牽強。

如果要討論 $「$ 盤」似乎也應該討論 $「$ 名」。「名」的上面也有人說是一片肉, $「 甘 」 」$ 有一點像, 但是有差。更不像兩條槓了。

多數文字學家把 $「 凡 」,\ulcorner$ 凡, 解釋 為「盤」的初文; 的確有點像。但是如果我們 研究這個字的拓樸, 我們發現好像缺乏「舟」的傾斜角度, 而且兩條栱槓好像太接近了 一點。

\section{三、「鳳」及「風」}

$\ulcorner$ 鳳」這個字在甲骨文發現的早期羅振玉就討論過。他著有〈說鳳〉, 但是我看不懂。 $\ulcorner$ 鳳」寫成 $\ulcorner$ 是甲骨文晚期的事; 早期背上並沒有 $\ulcorner$ 月」 $。$ 有人將 $\ulcorner$ H」解釋成 $\ulcorner$ 天, 甚至有人說那是標音而將鳳解釋為形聲字都太過率強。《說文》中明白的說那是象形字。 依我之見，「鳳」頭上有冠、背上有翅膀。翅膀就是 $「 H 」$ 翅膀與板子、旗子對於學造 船工程、航空工程的人說來是同一回事; 當然為了滿足不同需求細節可能需要修改一下。 綜觀我們查到的各種「鳳」字, 至少 49 例, 各種姿態都有, 可見那些羽毛如何飄似乎 並非重點, 說是象形字應不為過。如果那幾條線的位置、數目等等資訊是該字的構成要 件就不可能在每次書寫時都不一樣。有人將羽毛解釋成「朋」或倒立的「豐」也是太牽 強。

$\left\ulcorner\right.$ 風」寫成「甘」的僅有一例 ${ }^{7}$ 。一般認為「風」「凡」「鳳」是異體字。我們可 將 $\ulcorner H 」$ 當成是 $\ulcorner$ 的簡體字。因此也可見 $\ulcorner$ 月」是 $\ulcorner$ 鳳」的最重要部件。依我的解 釋，「H」就是一面被吹得變形的旗子。「風」 $=\ulcorner$ 鳳」原因也在此。旗子與板子到底差 多少? 對學航太工程的人說來是一樣的; 只是材料可能有點不同。

\section{四、「服」、「前」及「受」}

\footnotetext{
5 丁致良: 《流體力學》, (台中市: 秀才書屋, 2013)。

${ }^{6}$ Ting Julian : 《Discrete Mathematics》, (AMAZON : creativespace, 2013)。

7 劉鶚: 《鐵雲藏龜之餘》, 1915 年, 7.11 。
} 


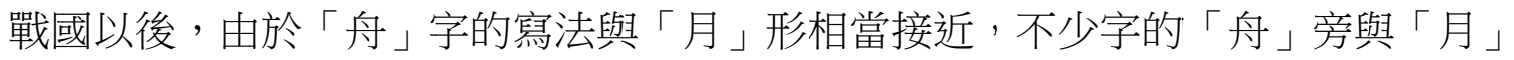
旁相混, 如「朕」「服」等。

$\ulcorner$ 服」「繁」的甲骨文左邊有一個 $「 月 」$ 有人解釋成方形木枷 + 人+手。有趣的是為 什麼手不是那個人的? 安也致及徐海寧則認為: 『舟』是追求徵兆時使用的靈物即龜甲, 跍拜的人物（還有被䟜拜的人物）是服從神靈的預先告知的表現。」這些都太牽強。為 什麼會想到罪犯? 我想到的怎麼是衣服? 在我看來這完全是個側身圖：一片布代表衣服 穿在人身上，當然那個人也有手。

$「$ 前」並沒有甲骨文。西周中期的金文中寫成「岁」。簡帛文、小管大致相同。部件 為「止」「舟」。

$\ulcorner$ 受」這個字有意思。「」, 中間是一葉扁舟, 前後兩隻手。其實那可能不是舟, 只是兩個人相互傳授的物品而已。

\section{五、「朕」}

$\ulcorner$ 朕」「级」特別被歸納為祭祀相關文字似乎沒有必要。祭祀符號的說法在白川靜的 《漢字百話》中也有 ${ }^{8}$ 。與其說某個符號是祭祀符號不如說那個符號只是象形符號, 而其 所象徵之物品, 旗子、酒杯等等, 卻是祭祀工具。段玉裁注：「戴先生曰：舟之縫理曰朕, 故札續之縫亦謂之朕, 所以補許書之佚文也。本訓舟縫, 引伸爲凡縫之偁。凡言朕兆者, 謂其幾甚微。如舟之縫, 如龜之坼也。」也太牽強。

在我看來, 那是一個背上插了個旗子的人; 還有兩隻手呢。相信大家看過京劇中將 軍出場都是背上插滿旗子。背上插不下的就由前面的旗隊拿著；媽祖出巡時前面都有旗 隊。旗子昭告政權。旗子就像招牌標示空間領域也象徵威權。

\section{六、結語}

甲骨文字學發展至今已經一百多年了, 前輩學者多由國學觀點探討甲骨文的意義, 且著作多用手抄。在資訊科技的時代新人應該使用新方法。物理學家研究問題的手法之 一是將問題抽象化; 在變與不變間研究事物中共同的特點。本文依照流體力學的看法將 板子、翅膀、船、肉片、布塊、旗子都看成相同的東西。同時我們提出拓樸學的觀念, 希望能更進一步分析甲骨文的原意。

8 白川清爭, 《漢字百話》, (新北市大家出版, 2012)。 


\section{參考書目}

口 朱岐祥, 《甲骨文讀本》, (台北市：里仁書局, 1999 年)。

- 安也致、徐海寧 : 〈古代亀卜文化の字における表現ついて 一一員「船」 形偏旁の意味の検討 〉《駒沢史学 駒沢史学》52 号，1999 年。

- 出野文莉：〈甲骨文 $\ulcorner$ 月」符號之原義〉《第 27 屆中國文字學國際學術研討會論 文集》, 2016 年。

- 丁致良：《流體力學》, (台中市 : 秀才書屋, 2013)。

- Ting Julian : 《Discrete Mathematics》, (AMAZON : creativespace, 2013)。

- 劉鶚 : 《鐵雲藏龜之餘》, 1915 年。

- 白川靜, 《漢字百話》, (新北市：大家出版, 2012)。 